\title{
Quality of Cucumbers Commercially Fermented in Calcium Chloride Brine without Sodium Salts
}

\author{
Erin K. McMurtrie ${ }^{1}$ and Suzanne D. Johanningsmeier $\mathbb{D}^{2}$ \\ ${ }^{1}$ Department of Food, Bioprocessing and Nutrition Sciences, North Carolina State University, 400 Dan Allen Drive, \\ Raleigh, NC 27695-7642, USA \\ ${ }^{2}$ USDA-ARS, SEA Food Science Research Unit, 322 Schaub Hall, Box 7624, North Carolina State University, \\ Raleigh, NC 27695-7624, USA
}

Correspondence should be addressed to Suzanne D. Johanningsmeier; suzanne.johanningsmeier@ars.usda.gov

Received 1 October 2017; Revised 5 December 2017; Accepted 20 December 2017; Published 26 March 2018

Academic Editor: Susana Fiszman

Copyright (c) 2018 Erin K. McMurtrie. This is an open access article distributed under the Creative Commons Attribution License, which permits unrestricted use, distribution, and reproduction in any medium, provided the original work is properly cited. Dr. Suzanne D. Johanningsmeier's contribution to this article is a work of the United States Government, for which copyright protection is not available in the United States. 17 U.S.C. $\$ 105$.

\begin{abstract}
Commercial cucumber fermentation produces large volumes of salty wastewater. This study evaluated the quality of fermented cucumbers produced commercially using an alternative calcium chloride $\left(\mathrm{CaCl}_{2}\right)$ brining process. Fermentation conducted in calcium brines $\left(0.1 \mathrm{M} \mathrm{CaCl}_{2}, 6 \mathrm{mM}\right.$ potassium sorbate, equilibrated) with a starter culture was compared to standard industrial fermentation. Production variables included commercial processor $(n=6)$, seasonal variation (June-September, 2 years), vessel size (10,000-40,000 L), cucumber size (2.7-5.1 cm diameter), and bulk storage time (55-280 days). Cucumber mesocarp firmness, color, bloater defects, $\mathrm{pH}$, and organic acids were measured. Complete lactic acid fermentation was achieved, resulting in terminal fermentation $\mathrm{pH}$ values of $3.23 \pm 0.09$ and $3.30 \pm 0.12$ for $\mathrm{CaCl}_{2}$ and $\mathrm{NaCl}$ processes, respectively. On average, $\mathrm{CaCl} \mathrm{Cb}_{2}$ brined, fermented cucumbers were $1.8 \mathrm{~N}$ less firm, which remained significant in the finished product $(P<0.0001)$. Color differences evidenced by higher hue and lower chroma values $(P<0.0269)$ were consistent with increased photooxidation in $\mathrm{CaCl}_{2}$ brined cucumbers. Commercial implementation of $\mathrm{CaCl}_{2}$ brines for cucumber fermentation in open tanks variably resulted in texture and color defects that can impact product quality. Additional research is needed to understand the atypical softening observed at the commercial scale and identify process controls for quality improvements.
\end{abstract}

\section{Introduction}

Commercial cucumber fermentation is a preservation method that depends on high sodium chloride $(\mathrm{NaCl})$ concentrations. Each fermentation is conducted in a 10,000 to $40,000 \mathrm{~L}$ open-top tank containing at least $0.86 \mathrm{M}(5 \%) \mathrm{NaCl}$ after equilibration with the fresh cucumbers. This salt concentration enables a natural fermentation to occur by selecting for the lactic acid bacteria present on the cucumbers and inhibiting salt-sensitive spoilage bacteria. The fermented cucumbers are then desalted to palatable salt levels by removing the fermentation brine and soaking the fermented cucumbers in fresh water. This process reliably produces high quality, fermented pickle products but generates significant volumes of high salt wastewater with chloride concentrations well above the EPA's Secondary Drinking Water Standards of less than $250 \mathrm{ppm}$ or $7 \mathrm{mM}$ chloride [1]. To lessen the amount of salt in wastewater, spent fermentation brines are now commonly stored and reused in subsequent fermentations [2]. Despite extensive reuse of spent brines, processors still routinely produce high volumes of salty wastewater from the desalting process. Pérez-Díaz et al. [3] estimated that the production of fermented cucumber pickles in the United States resulted in 45 million liters of wastewater containing $0.58 \mathrm{M} \mathrm{NaCl}$ from desalting processes, 1.3 billion liters of wastewater with $79 \mathrm{mM}$ chlorides, and 12,000 tons of salt sludge solid waste.

An alternative fermentation process utilizing $0.1 \mathrm{M}$ calcium chloride $\left(\mathrm{CaCl}_{2}\right), 0.025 \mathrm{M}$ acetic acid, and a Lactobacillus plantarum starter culture was developed by McFeeters and Pérez-Díaz [4]. Complete fermentation with fermented 
cucumbers that maintained their firmness was achieved without using any $\mathrm{NaCl}$ and an $80 \%$ lower chloride content. Since the development of this process, attempts to commercialize the technology have resulted in slight adjustments of the brine formulation and process. These adjustments included the elimination of acetic acid from the brine formulation, addition of $6 \mathrm{mM}$ potassium sorbate, and introduction of a minimal air-purging routine [3]. A typical purging routine utilizes the flow of air or nitrogen gas through the brine during the active fermentation period to help encourage the removal of carbon dioxide [5-7]. Carbon dioxide $\left(\mathrm{CO}_{2}\right)$ is produced as a product of heterofermentative fermentation, malolactic fermentation, and cucumber respiration $[5,6,8-$ 11]. An excess concentration of $\mathrm{CO}_{2}$ can cause hollow cavities in the flesh of the cucumber that constitute physical defects called bloaters. Both air and nitrogen purging have been suggested for use and implemented in commercial fermentation to remove $\mathrm{CO}_{2}$ from the brine to minimize bloater damage. Nitrogen purging is ideal since air purging can introduce oxygen into the fermentation tanks allowing aerobic microorganisms to flourish and reducing the texture quality of the fermented cucumbers $[12,13]$. However, air purging is less costly and used by most processors in combination with potassium sorbate to inhibit yeasts and molds. During the early stages of commercialization, fermentations using the alternative $\mathrm{CaCl}_{2}$ process were found to spoil much more easily than in the current commercial process. Therefore, the air-purging routine was altered to minimize the introduction of oxygen and potassium sorbate was added as a preservative against yeast spoilage [3]. Acetic acid can serve as a substrate for oxidative spoilage yeasts such as Issatchenkia occidentalis and Pichia manshurica [14], so it was removed from the brine formulation as well [3].

Pickles produced commercially using this modified, alternative fermentation process have shown variable results with regard to cucumber firmness. In the laboratory development of the process, mesocarp firmness of cucumbers fermented in this $\mathrm{CaCl}_{2}$ brine was found to be consistently comparable to the cucumbers fermented in a commercial brine formulation [4]. In contrast, cucumbers fermented in 12,500 L open-top tanks with the postcommercialization formulation changes showed variability in mesocarp firmness values as well as lower sensory hardness, fracturability, crispness, and crunchiness scores in some pickle products fermented and stored in $\mathrm{CaCl}_{2}$ brines [3]. Consumer testing also showed a decreased texture liking for cucumber pickles commercially produced with the $\mathrm{CaCl}_{2}$ brining process in some, but not all, experiments [15]. The objective of this study was to perform a large scale evaluation of commercial cucumber fermentation to determine the variability in physical, textural, and color quality of cucumbers fermented using the $\mathrm{CaCl}_{2}$ brining process and typical $\mathrm{NaCl}$ brining process during routine commercial production of hamburger dill chips.

\section{Materials and Methods}

2.1. Commercial Scale Cucumber Fermentation. Pickling cucumbers grown throughout the United States over the 2013 and 2014 seasons were fermented in 10,000 to 40,000 L opentop tanks at six processing facilities. Fermentation was initiated between the months of June and September each year. Fermentation tanks contained size $2 \mathrm{~A}(2.7-3.5 \mathrm{~cm}$ diameter), 2B (3.5-3.8 cm diameter), 3A (3.8-4.4 cm diameter), or 3B (4.4-5.1 cm diameter) cucumbers covered with a fermentation brine. Fermentation brines for the control fermentation were prepared using the current commercial process and were comprised of recycled brines with additional $\mathrm{NaCl}$, $\mathrm{CaCl}_{2}$, and potassium sorbate such that the cucumbers equilibrated to approximately $1.0 \mathrm{M} \mathrm{NaCl}, 40 \mathrm{mM} \mathrm{CaCl}_{2}$, and $2 \mathrm{mM}$, respectively. Fresh brines for the $\mathrm{CaCl}_{2}$ brining process were prepared to equilibrate with the cucumbers to concentrations of $100 \mathrm{mM} \mathrm{CaCl}_{2}$ and $6 \mathrm{mM}$ potassium sorbate. In total, 41 tanks of cucumbers were fermented using the $\mathrm{CaCl}_{2}$ brining process along with 27 tanks of cucumbers fermented in $\mathrm{NaCl}$ brines using standard industry practices.

Each fermentation process began with the addition of cushion brines (18-20 inches deep) to the tanks to minimize damage as the cucumbers were added. Cucumbers were added to the tanks and wooden boards were placed over the cucumbers to ensure that they stayed submerged under the brine during fermentation. Brines were then added to the tanks and the $\mathrm{CaCl}_{2}$ brined cucumbers were inoculated with $10^{5}-10^{6} \mathrm{CFU} / \mathrm{mL}$ L. plantarum starter culture (LA0445 or other presumptive L. plantarum isolates from cucumber fermentation (unpublished), USDA-ARS, Food Science Research Unit, Raleigh, NC, USA, culture collection) prepared according to the kosher process described by PérezDíaz and McFeeters [16]. Sodium chloride brined cucumbers underwent a natural fermentation and were air-purged for the duration of active fermentation in cycles of $8 \mathrm{~h}$ followed by a $4 \mathrm{~h}$ reprieve (processor 1 ) or $20 \mathrm{~h}$ per day (all other processors). During the 2013 season, $\mathrm{CaCl}_{2}$ brined cucumbers at processor 1 received a minimal purge cycle of only $2 \mathrm{~h}$, twice a day, but followed the same purge routine as the $\mathrm{NaCl}$ tanks during the 2014 season. All other processors used their typical air-purging routine of $20 \mathrm{~h}$ per day for all fermentations.

Fermented cucumbers were bulk stored in the fermentation brines for 55 to 280 days and then processed into finished products according to routine processing schedules. Prior to processing, a 5 gallon sample of cucumbers and brine was collected for analysis, hereafter referred to as "fermented" samples. Processing of the $\mathrm{CaCl}_{2}$ brined cucumbers utilized a two-step desalting procedure that entailed the pumped removal of the fermentation brine and replacement with fresh water. This was allowed to equilibrate for a day, during which the cucumbers were air-purged for $2 \mathrm{~h}$ before the liquid was pumped out again. Freshly made $0.2 \%$ alum water was added to the tanks and allowed to equilibrate with the fermented cucumbers for a second day, again with $2 \mathrm{~h}$ of purging. The $\mathrm{NaCl}$ brined tanks followed a one-step desalting procedure where the fermentation brine was removed and replaced with $0.2 \%$ alum water and allowed to equilibrate with the fermented cucumbers for 1 day. A 5 gallon sample of cucumbers and brine was collected for analysis just before packaging into finished product, referred to as "Desalted" samples. The alum water was then pumped out of the tank and the cucumbers were conveyed to the packing line for cutting, 
packing, addition of freshly prepared cover liquor, capping, and pasteurization using standard practices. Cover liquors were formulated for each fermentation process to create finished products that equilibrated to the processor's desired product specifications such that cucumbers fermented in $\mathrm{CaCl}_{2}$ and cucumbers fermented in $\mathrm{NaCl}$ would be stored as finished product with equivalent concentrations of $\mathrm{NaCl}$, $\mathrm{CaCl}_{2}$, vinegar, and flavors. Finished products (at least 3 jars per fermentation) were collected near the beginning, middle, and end of processing of each tank of fermented cucumbers and stored for 6 months at ambient temperature prior to analysis as "finished product" samples.

2.2. Bloater Defects. Bloater type and severity were recorded for 25 fermented and 25 desalted cucumbers per fermentation. Each cucumber was sliced longitudinally and evaluated according to the bloater chart developed by Etchells and others [17]. Bloater indices were calculated as described by Fleming and others [18].

2.3. Texture Analysis. Instrumental firmness measurements were performed using a mesocarp puncture test. A $6.7 \pm$ $0.1 \mathrm{~mm}$ slice was taken from the center of 30 cucumbers for the raw, fermented, and desalted samples. Finished products were crinkle cut using a commercial slicer, packed into jars, and pasteurized. After ambient storage for 6 months, 30 crinkle cut slices were collected from the top, middle, and bottom of 3 jars as the test samples for finished products. The mesocarp puncture test was conducted on a TA.XT Plus Texture Analyzer (Texture Technologies Corp, Scarsdale, NY/Stable Micro Systems, Godalming, Surrey, UK) using a $3 \mathrm{~mm}$ probe to puncture the mesocarp tissue at a test speed of $2.5 \mathrm{~mm} / \mathrm{sec}[19,20]$. The mesocarp of one lobe of each slice was centered above a $3.1 \mathrm{~mm}$ hole on the base plate and the probe was lowered through the sample. The test was conducted and data was analyzed using Texture Expert software (version 6.1.3.0, Texture Technologies Corp.). The peak force measured during the puncture test and the thickness of each slice were determined and recorded to create an average peak force and average slice thickness for each tank of fermented cucumbers at fermented, desalted, and finished product processing stages.

2.4. Color Analysis. Cucumber mesocarp color was measured using a Minolta Chroma Meter model CR-300 (Minolta Co., Ltd., Osaka, Japan) to record the $L^{*}, a^{*}$, and $b^{*}$ values of a different lobe of each of the 30 slices used for firmness measurements. Each slice was placed on a representative fermented cucumber background at least 1.5 inches high to account for translucency of the slices. Values of hue and chroma were calculated to convert the CIELAB color variables to the polar coordinate system CIELCH as follows:

$$
\begin{aligned}
\text { Hue } & =\tan ^{-1}\left(\frac{b^{*}}{a^{*}}\right) \\
\text { Chroma } & =\left(a^{* 2}+b^{* 2}\right)^{1 / 2},
\end{aligned}
$$

where hue indicates the pigment of the color and chroma indicates the intensity. A hue of $0^{\circ} / 360^{\circ}$ represents red, $90^{\circ}$, yellow, $180^{\circ}$, green, and $270^{\circ}$, blue.

2.5. Quantification of Fermentation Metabolites. Concentrations of organic acids, residual sugars, and some spoilage metabolites were quantified by High Performance Liquid Chromatography analysis using an Agilent 1260 Infinity HPLC (Agilent Technologies Inc., Santa Clara, CA, USA) equipped with an HPX-87H ion exchange column for organic acid analysis (Bio-Rad Laboratories, Hercules, CA, USA). Chromatography was conducted with $0.03 \mathrm{~N}$ sulfuric acid mobile phase at a flow rate of $0.6 \mathrm{~mL} /$ minute and column temperature of $37^{\circ} \mathrm{C}$. Organic acids were quantified using an Agilent 1260 Infinity DAD detector (Agilent Technologies Inc.) at $210 \mathrm{~nm}$. Monomeric sugars and alcohols were quantified using an Agilent 1260 Infinity RI detector (Agilent Technologies Inc.) connected in series with the $\mathrm{DAD}$ detector.

2.6. Chemical Analyses. A Fisher Accumet (model AR25) $\mathrm{pH}$ meter equipped with a pencil-tip gel-filled electrode calibrated with standardized $\mathrm{pH} \mathrm{2,} \mathrm{4,} \mathrm{and} 7$ buffers (Fisher Scientific, Waltham, MA, USA) was used for $\mathrm{pH}$ measurement. Calcium concentrations were determined by titration with $0.025 \mathrm{~N}$ disodium ethylenediaminetetraacetate dihydrate (EDTA) with hydroxy naphthol blue as the indicator according to AOAC Method 968.31 [21]. Sodium chloride concentrations were estimated by Fajan's chloride titration using $0.171 \mathrm{~N}$ silver nitrate $\left(\mathrm{AgNO}_{3}\right)$ and a dichlorofluorescein indicator [22]. Reported values for $\mathrm{NaCl}$ were calculated by subtracting the chloride contributed by $\mathrm{CaCl}_{2}$ from the total chloride content using the formula $[\mathrm{NaCl}]=\left[\mathrm{Cl}^{-}\right]-$ $2 *\left[\mathrm{CaCl}_{2}\right]$, where the molar concentration of $\mathrm{CaCl}_{2}$ was presumed to be equal to the molar concentration of calcium.

2.7. Polygalacturonase Activity. Polygalacturonase (PG) activity was assayed using the diffusion plate assay developed by Buescher and Burgin [23]. Polygalacturonase activity was assayed for both brines and cucumbers. Cucumber homogenates were produced by blending the cucumbers from texture and color analysis in a Waring Blender. Briefly, an aliquot of $30 \mu \mathrm{L}$ of each brine or cucumber supernatant was pipetted into a well created by a size 4 cork borer in an agar plate containing polygalacturonic acid substrate. The agar plates were incubated at $38^{\circ} \mathrm{C}$ for $48 \mathrm{~h}$. After incubation, agar was stained for 30 minutes using ruthenium red which binds to polygalacturonic acid remaining in the medium. After staining, the plates were rinsed and destained in deionized water for $20 \mathrm{~h}$. The diameter of the clear zone around each sample well was measured using calipers. Clear zones indicated the activity of the enzyme as the dye will not bind to galacturonic acid residues.

2.8. Statistical Analysis. All results were analyzed using SAS statistical software (version 9.4, SAS Institute, Cary, NC, USA). A mixed model analysis of variance was used with least square means. Fermentation process $\left(\mathrm{NaCl}\right.$ or $\left.\mathrm{CaCl}_{2}\right)$, cucumber size, and stage in processing were designated as fixed 


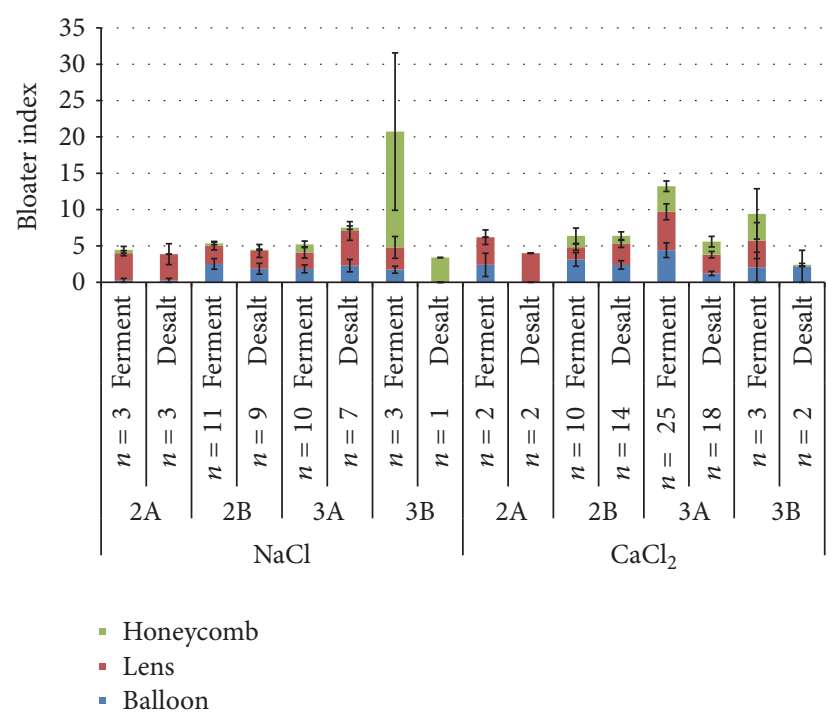

FIgURE 1: Total, balloon, lens, and honeycomb bloater indices for fermented and desalted cucumbers by cucumber size and brining process. Error bars represent standard error of the mean.

effects and the individual tanks of fermented cucumbers were designated as random effects. Statistical significance was indicated at $P<0.05$. Values are presented as means \pm standard deviation in Table 1. Data in Table 2 and Figure 1 are presented as means \pm standard error.

\section{Results and Discussion}

Raw cucumber samples, representative of those fermented, had initial mesocarp firmness of $8.7 \pm 0.9 \mathrm{~N}$, sugar content of $54.2 \pm 12.0 \mathrm{mM}$ glucose and $65.2 \pm 14.1 \mathrm{mM}$ fructose, and calcium content of $3.0 \pm 0.8 \mathrm{mM}$. The chemical compositions of fermented, desalted, and finished cucumber pickles produced with the typical, $\mathrm{NaCl}$-dependent commercial process and the alternative $\mathrm{CaCl}_{2}$ brining process are shown in Table 1. Complete fermentation was achieved with both processes, resulting in safe, insignificantly different terminal $\mathrm{pH}$ values of $3.23 \pm 0.09$ in the $\mathrm{CaCl}_{2}$ brined, fermented cucumbers and $3.30 \pm 0.12$ in cucumbers fermented with the current commercial process using $\mathrm{NaCl}$. Lactic and acetic acids were significantly higher in the $\mathrm{NaCl}$ fermentation process despite the insignificant difference in $\mathrm{pH}$ values, likely because recycled brines were used that contained residual acid generated in previous fermentation. It is possible that the terminal $\mathrm{pH}$ values were not significantly different from each other because of the different ratio of lactic to acetic acid. Lactic acid has a pKa of 3.86 which is much lower than the pKa of acetic acid, 4.76. Since the $\mathrm{NaCl}$ brined cucumbers had greater acetic acid to lactic acid ratio, the $\mathrm{pH}$ could be insignificant because of greater buffering. Due to the presence of residual acid in recycled brines, the $\mathrm{NaCl}$ brines started with a lower initial $\mathrm{pH}$ than the $\mathrm{CaCl}_{2}$ brines which were not acidified prior to fermentation. The additional acid in the $\mathrm{NaCl}$ brines may contribute to higher buffering capacity and may influence the $\mathrm{pH}$ during early fermentation. Indeed, the fermentation in $\mathrm{NaCl}$ brines had an average brine $\mathrm{pH}$ of $3.6 \pm$ 0.4 after 1 day of fermentation, while the experimental fermentation in $\mathrm{CaCl}_{2}$ brines had an average brine $\mathrm{pH}$ of $4.9 \pm$ 0.2 after 1 day based on the quality control data collected by the commercial processors.

A desalting step was used in both fermentation processes to lower the $\mathrm{NaCl}$ to palatable concentrations or to lower the $\mathrm{CaCl}_{2}$ concentration to below the legal limit of $36 \mathrm{mM}$ in the finished product (21 CFR 184.1193) [24]. The $\mathrm{pH}$ values, $\mathrm{CaCl}_{2}, \mathrm{NaCl}$, lactic acid, and acetic acid concentrations for $\mathrm{CaCl}_{2}$ and $\mathrm{NaCl}$ brined fermented cucumbers were affected by the desalting process as expected (Table 1). During desalting, the $\mathrm{pH}$ rose to $3.47 \pm 0.28$ for cucumbers fermented in $\mathrm{CaCl}_{2}$ brines and $3.40 \pm 0.19$ for those in $\mathrm{NaCl}$ brines as the lactic acid and acetic acid concentrations were diluted along with the salts (Table 1). Although the desalted, $\mathrm{NaCl}$ brined cucumbers contained significantly more lactic and acetic acids than the desalted $\mathrm{CaCl}_{2}$ brined cucumbers, the $\mathrm{pH}$ values did not differ significantly, likely due to the buffering capacity of the system. The lactic and acetic acid concentrations were much lower in the desalted cucumbers fermented in $\mathrm{CaCl}_{2}$ brines, because they were desalted twice to reduce the $\mathrm{CaCl}_{2}$ concentrations to that of the typical commercial products.

In the production of finished pickle products, desalted cucumbers were separated from the desalting water before being cut and packed with freshly made cover liquor containing sufficient $\mathrm{NaCl}, \mathrm{CaCl}_{2}$, vinegar, and flavors, such as dill, to equilibrate to each processor's desired formulation. Processors measured salt and acid concentrations in the desalting solutions to calculate the concentrations of ingredients for the cover liquor to equilibrate with the desalted cucumbers to the specifications for the product they were making. Because these specifications vary based on the type of pickle product made and between brands, there was greater variability in the composition of the finished product samples (Table 1). However, since the cover liquors were made for each batch, the concentrations of acetic acid, $\mathrm{NaCl}$, and/or $\mathrm{CaCl}_{2}$ were able to equilibrate to the processors' target concentrations. Despite the differences in the composition of the desalted fermented cucumbers from the two processes, processors were able to produce hamburger dill chips within the normal compositional range of current products.

3.1. Bloater Defects. Bloater defects are formed by an excess of $\mathrm{CO}_{2}$ in the fermenting cucumbers that builds pressure, breaking cell walls [8]. Bloater indices indicating the type and severity of bloaters were calculated for balloon, lens, and honeycomb type bloaters as well as total bloaters (Figure 1) according to Fleming et al. [18]. Overall, the fermentation in $\mathrm{CaCl}_{2}$ brines produced fermented cucumbers with higher bloater indices $\left(\mathrm{CaCl}_{2}: 10.5 \pm 1.7 ; \mathrm{NaCl}: 9.8 \pm 1.9\right)$; however, this difference was not statistically significant due to large tank to tank variability. Although the brining process alone did not significantly affect lens, balloon, or total bloaters $(P>0.3878)$, it was significant for honeycomb bloaters $(P=$ 0.0226 ). Size $3 \mathrm{~B}, \mathrm{NaCl}$ brined cucumbers had significantly higher honeycomb bloater indices than any other treatment $(P<0.0006)$. However, there were only a few fermentation 


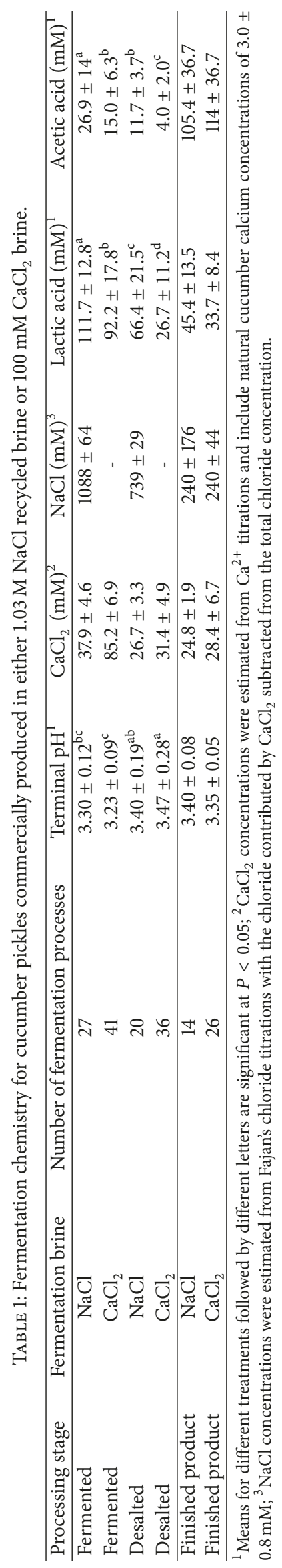




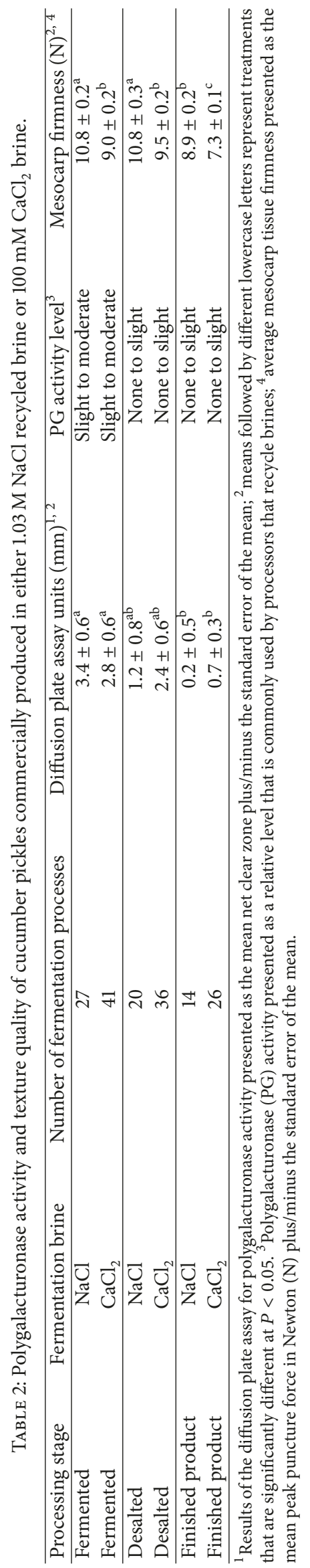


tanks of this type and a single fermentation with high occurrence of honeycomb bloating may have skewed the results. Other bloater indices were highly variable and not accounted for solely by brine type (Figure 1). In the 2013 season, the occurrence of moderately to severely bloated cucumbers was significantly higher in fermentation in $\mathrm{CaCl}_{2}$ brines (data not shown). The alternative purging routine used in the experimental tanks was suspected to affect the incidence of bloaters because of lessened removal of $\mathrm{CO}_{2}$ from the fermentation brines, so processors increased the air-purging routine in $\mathrm{CaCl}_{2}$ brined cucumbers to match that of their $\mathrm{NaCl}$ brining process for subsequent fermentations. Brining season was found to be significantly correlated with the bloater index $(P=0.0019)$. This could be impacted by a number of uncontrolled production variables, such as cultivar, farm location, and rainfall, but was more likely due to the modification in the purging routine between seasons. The use of the minimal purging routine with the $\mathrm{CaCl}_{2}$ process was found to significantly correlate with the total bloater indices $(P=0.0258$, Figure 2). Using $\mathrm{CaCl}_{2}$ brines with standard air-purging routines reduced bloating to levels much closer to the current commercial process. Purging procedures were developed to minimize the accumulation of $\mathrm{CO}_{2}$ gas that can cause bloaters, but the introduction of oxygen into the nearly anaerobic fermentation environment can be an impediment to successful fermentation by $\mathrm{LAB}$ in the $\mathrm{CaCl}_{2}$ fermentation process. However, the use of a minimal purge routine appears to be a detriment to cucumber pickle quality. The variability in quality associated with the use of the minimal purging routine indicates a need for further optimization of purging routines to consistently obtain a high quality product with this fermentation process.

3.2. Texture Quality. Raw cucumber mesocarp firmness was $8.7 \pm 0.9 \mathrm{~N}$ and the firmness after fermentation and bulk storage was $9.0 \pm 1.7$ when brined with $\mathrm{CaCl}_{2}$ or $10.8 \pm 1.1$ after natural fermentation in recycled $\mathrm{NaCl}$ brines. These differences between brining processes were first detected at the fermented stage and were detected thereafter at the desalted and finished product stages (Figure 3). Cucumbers brined in $\mathrm{CaCl}_{2}$ for fermentation and storage had an average peak force $1.7 \mathrm{~N}$ lower than those brined in $\mathrm{NaCl}$ across all processing stages. Average calcium concentrations of $85.2 \pm 6.9$ and $37.9 \pm 4.6 \mathrm{mM}$ were slightly lower than the intended $100 \mathrm{mM}$ and $40 \mathrm{mM}$ for the respective treatments. Variability in the ratio of cucumbers to brine used in the fermentation and the purity of the $\mathrm{CaCl}_{2}$ ingredient could contribute to the lower than targeted calcium content measured in the commercially fermented cucumbers. In laboratory experiments, cucumbers fermented and stored in $100 \mathrm{mM}, 200 \mathrm{mM}$, and $300 \mathrm{mM}$ $\mathrm{CaCl}_{2}$ brines without $\mathrm{NaCl}$ have been shown to produce fermented cucumbers with mesocarp firmness comparable to cucumbers fermented and stored in a $1.03 \mathrm{M} \mathrm{NaCl}$ and $40 \mathrm{mM} \mathrm{CaCl}_{2}$ brine for 8 months [4]. The range observed in our commercial study $(70.5-98.3 \mathrm{mM} \mathrm{CaCl} 2)$ was below the targeted $100 \mathrm{mM}$, known to maintain firmness in laboratory studies [4]. However, the minimum $\mathrm{CaCl}_{2}$ concentration to retain firmness in the absence of $\mathrm{NaCl}$ is unknown, and the $\mathrm{CaCl}_{2}$ concentration in $\mathrm{CaCl}_{2}$-brined, fermented cucumbers

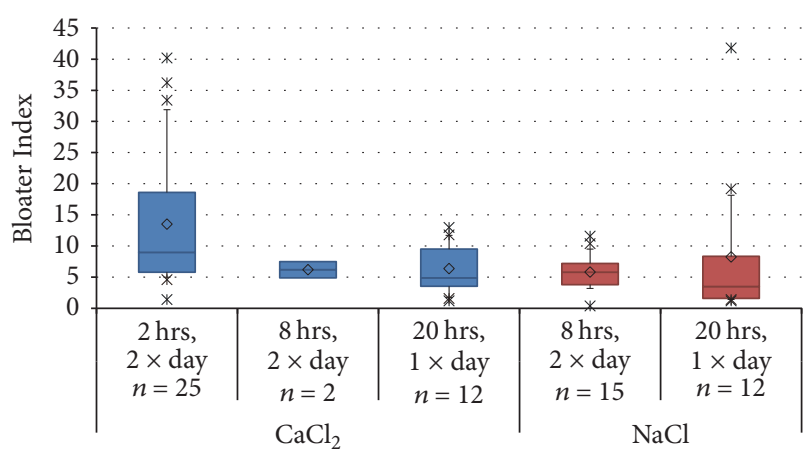

Figure 2: Bloater indices for fermented cucumbers by brining process and purging procedure. The minimal purging routine of $2 \mathrm{~h}$, 2 times a day was only used in $\mathrm{CaCl}_{2}$ brines. The $8 \mathrm{~h}, 2$ times per day ( $2 \times$ day) treatment was used by processor 1 and the $20 \mathrm{~h}, 1$ time per day $(1 \times$ day $)$ treatment was used by the remaining processors.

had no correlation with mesocarp firmness in this study $(P=$ 0.9917). Thus, there is likely another factor affecting the texture quality of cucumbers fermented with the $\mathrm{CaCl}_{2}$ brining process on the commercial scale.

Other commercially relevant variables were investigated for explaining the variability in fermented cucumber firmness independently of the brining process. Time spent in bulk storage was found to negatively correlate with fermented cucumber mesocarp firmness relating to a loss of $\sim 0.7 \pm 0.2 \mathrm{~N}$ over 100 days regardless of fermentation process (Figure 4). The effect of the time spent in bulk storage on texture became more discernible as the cucumbers were processed into desalted and finished product samples with $0.8 \pm 0.2 \mathrm{~N}$ and $1.1 \pm 0.2 \mathrm{~N}$ lower peak forces for every 100 days, respectively. Firmness was higher in smaller diameter cucumbers $(P=$ 0.0187 ), consistent with previous findings by Sistrunk and Kozup [25]. Rosenberg [26] also found that size 2B cucumbers had significantly firmer mesocarp tissue than size $3 \mathrm{~A} \mathrm{cu}-$ cumbers in both the $\mathrm{NaCl}$ and $\mathrm{CaCl}_{2}$ fermentation processes, but the difference in texture was not detected with a whole cucumber fruit pressure test that is commonly used by the industry for monitoring texture quality during processing.

Polygalacturonase, an enzyme known for softening of cucumber pickles [27-29], was assayed, but no significant differences between brining processes $(P=0.4470)$ nor correlations between PG and mesocarp firmness were found for fermented, desalted, or finished product samples in this study (Table 2). On average, PG activity levels were low in both brining processes and further decreased in samples after desalting and finished product processing. Furthermore, the levels of calcium in the two processes should be sufficient to prevent enzymatic tissue softening at these low PG activities $[29,30]$, which is congruent with the lack of correlation between PG activity and firmness values observed.

Organic acids have been shown to cause nonenzymatic softening of fresh pack cucumber pickles [31], so it was of interest whether the different concentrations of lactic and acetic acids in industrial fermentation would be related to texture quality. Lactic acid (as little as $26 \mathrm{mM}$ ) has been shown to cause softening over time in low salt $(2 \% \mathrm{NaCl})$ conditions 


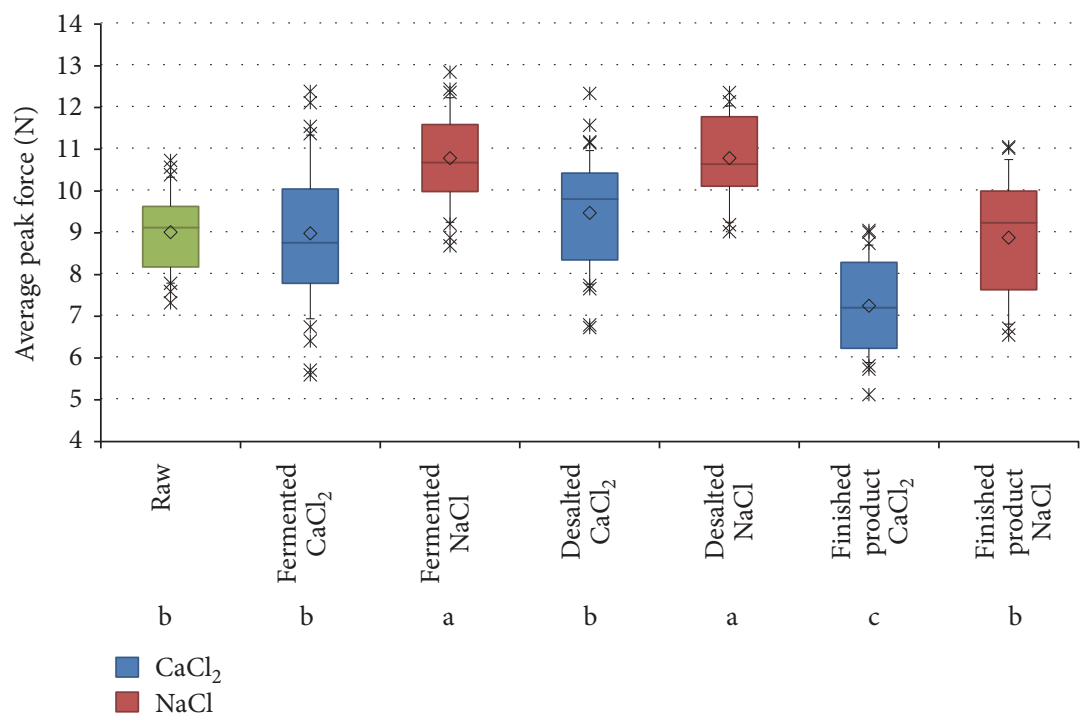

Figure 3: Mesocarp firmness (N) for cucumbers brined in $\mathrm{CaCl}_{2}$ compared with $\mathrm{NaCl}$ at the various stages in processing. Peak force values were significantly different between brining processes at each stage but were not significantly different between fermented and desalted stages. Peak forces were significantly different at $P<0.05$ for treatments as signified by different lowercase letters below the $x$-axis treatment labels.

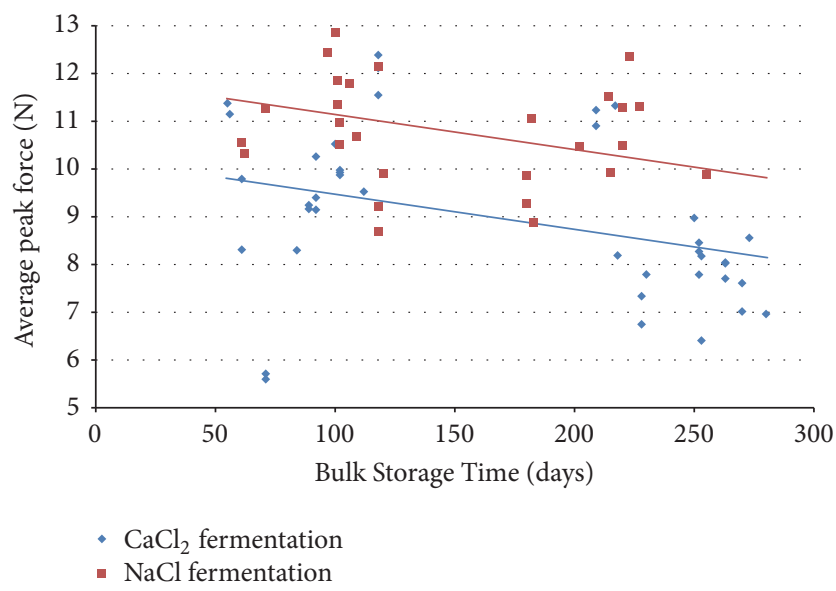

FIGURE 4: Differences in mesocarp firmness associated with increased time spent in bulk storage. Each data point represents the average mesocarp firmness for a 30-cucumber sample from each independent commercial cucumber fermentation tank.

with higher concentrations of lactic acid causing greater softening [31]. In this commercial study, lactic acid concentrations varied between $\mathrm{CaCl}_{2}$ brined cucumbers $(92.22 \pm$ $17.83 \mathrm{mM})$ and $\mathrm{NaCl}$ brined cucumbers $(111.7 \pm 12.8)$ during bulk storage, but the firmness of fermented cucumbers was not correlated to lactic acid concentration $\left(\mathrm{CaCl}_{2}: P=\right.$ $0.2071, \mathrm{NaCl}: P=0.4636)$ or acetic acid concentration $\left(\mathrm{CaCl}_{2}: P=0.3647 ; \mathrm{NaCl}: P=0.1577\right)$. Calcium has previously been shown to minimize the softening induced by acid $[32,33]$. Although softening has been shown in fresh pack cucumbers at the concentrations of lactic acid in these fermentation brines, it is possible that the fermentation process and/or the inclusion of $\mathrm{CaCl}_{2}$ in the fermentation brine minimized acid-induced softening. Only brining process, cucumber size, and time in bulk storage were significantly influencing the texture quality of the commercially fermented cucumbers in this study.

Two major differences between the laboratory fermentation in $\mathrm{CaCl}_{2}$ brines that maintained equivalent texture quality and the commercial fermentation in this study are the level of oxygen exposure and initial brine acidification. Both of these factors could influence the microbiota and biochemical changes during the initiation of fermentation. Commercial fermentation is conducted in open-air tanks and air-purging is applied during the active fermentation period. The additional oxygen from the air could alter the microbiota, allowing salt-sensitive, aerobic organisms with pectinolytic activities to influence product quality of $\mathrm{CaCl}_{2}$ brined cucumbers. The fermentation microbiota as well as enzymatic and nonenzymatic softening activities in cucumber tissue could also be influenced by the lack of initial brine acidification in the commercial $\mathrm{CaCl}_{2}$ brines. The greater availability of oxygen in combination with higher levels of calcium may also induce oxidative softening. There is some evidence that calcium can act indirectly as a prooxidant by preferentially binding to natural chelators, making them unavailable to bind prooxidant metals such as iron [34]. Further research is needed in two key areas: (1) to determine the influence of oxygen and initial brine acidification on the microbiota of low or no salt fermentation during the first few days after brining; and (2) to investigate the combined effects of oxygen, sodium, and calcium on chemical and biochemical reactions during cucumber fermentation that impact product quality.

No degradation or enhancement of texture quality was observed during desalting. Desalting did not significantly affect the mesocarp firmness for either brining process $(P=$ 0.2891). The inclusion of alum in desalting water has been 
shown to increase the firmness of fermented cucumbers, but this has been found to be insignificant if $0.3 \% \mathrm{CaCl}_{2}$ is included in the fermentation brine [35]. At least $0.3 \% \mathrm{CaCl}_{2}$ was included in the fermentation brine of both treatments, so it is not surprising that the mesocarp firmness of desalted cucumbers was not significantly different from the fermented cucumbers. It is also reassuring that no further degradation in texture quality occurred at this stage of processing.

Finished hamburger dill chip products from both brining treatments were considerably lower in mesocarp peak force $(N)$ than the fermented and desalted cucumbers. All raw, fermented, and desalted samples were obtained as whole cucumbers and cut manually by a hand operated food slicer to slices measured to be $6.7 \pm 0.1 \mathrm{~mm}$. However, the finished products were cut into crinkle cut chips by commercial slicers as is sold on store shelves. The commercial slicers were less precise and produced thinner chips that were $3.8 \pm 0.7 \mathrm{~mm}$ thick. Thompson et al. [19] found that slices less than $3.2 \mathrm{~mm}$ had significantly reduced peak force measurements, but slice thicknesses between $4.8-9.5 \mathrm{~mm}$ did not significantly affect peak puncture force measurement. Since most of the finished product slices were between $3.2 \mathrm{~mm}$, where the effect of thickness on firmness is known to be significant, and $4.8 \mathrm{~mm}$, the range where the effect of thickness on firmness is known to be insignificant, it is unclear whether slice thickness may be influencing the lower instrumental firmness of finished products. An alternate explanation for the overall lower firmness of finished products could include the softening of finished products during the pasteurization process. Higher pasteurization temperatures and longer processes have been previously correlated with softer finished product [36]. Despite the overall reduction in mesocarp firmness in the finished products, the cucumber pickles fermented in $\mathrm{NaCl}$ brine were still significantly firmer than those fermented with the $\mathrm{CaCl}_{2}$ process by $1.6 \mathrm{~N}$. Instrumental mesocarp firmness values are well correlated with sensorial measurements of firmness, crispness, hardness, and crunchiness [3, 19, 20, 37, 38]. Wilson et al. [15] found significant differences in hedonic texture liking for hamburger dill chips produced from cucumbers preserved by $\mathrm{NaCl}$ and $\mathrm{CaCl}_{2}$ fermentation processes that were $1.1 \mathrm{~N}$ different in instrumental firmness values. Therefore, it is likely that a consumer would notice the $1.6 \mathrm{~N}$ difference in firmness values for pickle products from the $\mathrm{NaCl}$ and $\mathrm{CaCl}_{2}$ fermentation processes.

3.3. Mesocarp Color. Cucumber mesocarp color was evaluated by colorimetric analysis using $L^{*} a^{*} b^{*}$ color space and converted to hue and chroma values. Cucumbers fermented with the $\mathrm{CaCl}_{2}$ process had significantly higher hue values compared to those fermented in $\mathrm{NaCl}$ brines at each stage in processing. Fermented cucumbers with average hue, chroma, and $L^{*}$ values very close to the means for each treatment are shown in Figure 5 to illustrate the significant difference in appearance. The differences in hue and chroma caused by brining treatment at different processing stages can be seen in Figures 6 and 7, respectively. Chroma was significantly higher in the finished product for each treatment than in the fermented and desalted stages. Chroma measures the intensity of a color and the addition of yellow 5 dye to the cover liquor showed a marked increase in the intensity of the mesocarp color $(P<0.0001$, Figure 7$)$ that masked some of the variability in appearance of the fermented cucumbers. The cucumbers fermented in $\mathrm{NaCl}$ brine also had significantly higher chroma values than their counterparts in the $\mathrm{CaCl}_{2}$ brine $(P=0.0269)$; however, this difference was no longer statistically significant after the desalting procedure $(P=0.1807)$.

Color changes occurring during cucumber fermentation are primarily a result of the degradation of chlorophyll. The degradation of chlorophyll to pheophorbide has been proposed to occur in plant products by two pathways, through pheophytin as an intermediate or through chlorophyllide as an intermediate [39]. Color changes in cucumbers exposed to acidic brines have been shown to occur by the production of a combination of pheophorbide and pheophytin pigments [40]. This degradation of brightly colored green chlorophyll to pheophorbide and pheophytin produces a dull olivegreen or olive-yellow color in food products [41]. Fermenting cucumbers have very small concentrations of chlorophyllide, but pheophytin accumulates in large concentrations, so it has been modeled that the accumulation of pheophorbide occurs predominantly using chlorophyllide as an intermediate, while the pathway from pheophytin to pheophorbide is rarely used $[39,42]$. At the beginning of fermentation in fresh, nonacidified brines, the $\mathrm{pH}$ is neutral, allowing the enzymatic conversion of chlorophyll to chlorophyllide by chlorophyllase to dominate the degradation reactions. Once the $\mathrm{pH}$ is lowered by fermentation, the acid causes the loss of magnesium $\left(\mathrm{Mg}^{2+}\right)$ from the center of the chlorin ring of the remaining chlorophyll or newly formed chlorophyllide to produce pheophytin and pheophorbide, respectively. This results in chlorophyll being converted to pheophytin directly or being converted to pheophorbide from the intermediate chlorophyllide, but the high acid environment makes the final concentration of chlorophyllide minimal.

The proposed mechanism was for nonacidified brines; however, commercial production of fermented cucumber pickles currently utilizes recycled acidic brines. This acid still must equilibrate into the cucumbers to degrade their chlorophyll molecules, but the acidified brines would likely result in less product proceeding through the enzymatic process to form chlorophyllide before acid reactions became more favorable. The brines for the $\mathrm{CaCl}_{2}$ process were not acidified and would more closely follow the previously detailed mechanism. This could, therefore, result in a higher ratio of pheophorbide: pheophytin in the cucumbers undergoing $\mathrm{CaCl}_{2}$ fermentation process. It is worth noting that pheophytin can also be converted to pheophorbide by chlorophyllase, but this reaction has not been measurably observed in fermenting cucumbers [39, 42].

In this study, the mesocarp chroma (intensity of the color) was lower with longer time spent in bulk storage and was generally lower in cucumbers fermented in $\mathrm{CaCl}_{2}$ brines (Figure 8). This decrease in chroma corresponds with the idea that the pigments may be degrading with greater exposure time to sunlight and oxygen. While the opaque tanks and the use of wooden boards to submerge the cucumbers minimize the exposure of the cucumbers to sunlight, the cucumbers are exposed during the first day, while tanking and the ultraviolet 

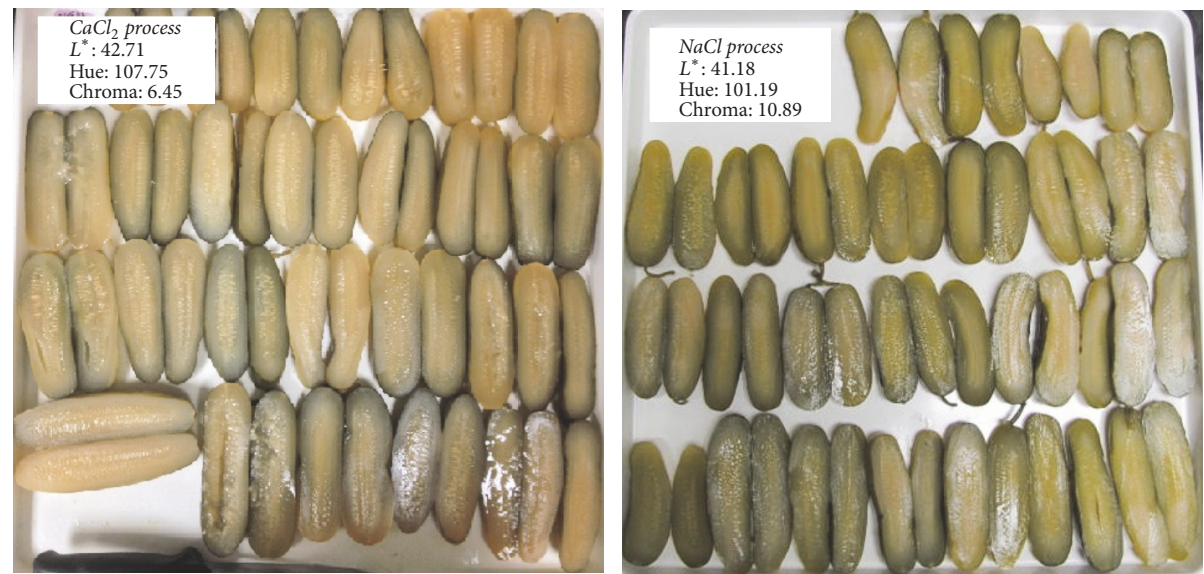

FIGURE 5: Fermented cucumbers representative of the average color of each fermentation process. The average hue value for the cucumbers in the $\mathrm{CaCl}_{2}$ fermentation process was significantly higher than the average hue of the cucumbers in the $\mathrm{NaCl}$ fermentation process $(P<$ $0.05)$. The chroma values were also significantly different $(P=0.0269)$, but the $L^{*}$ values were not significantly different from each other $(P=0.9432)$.

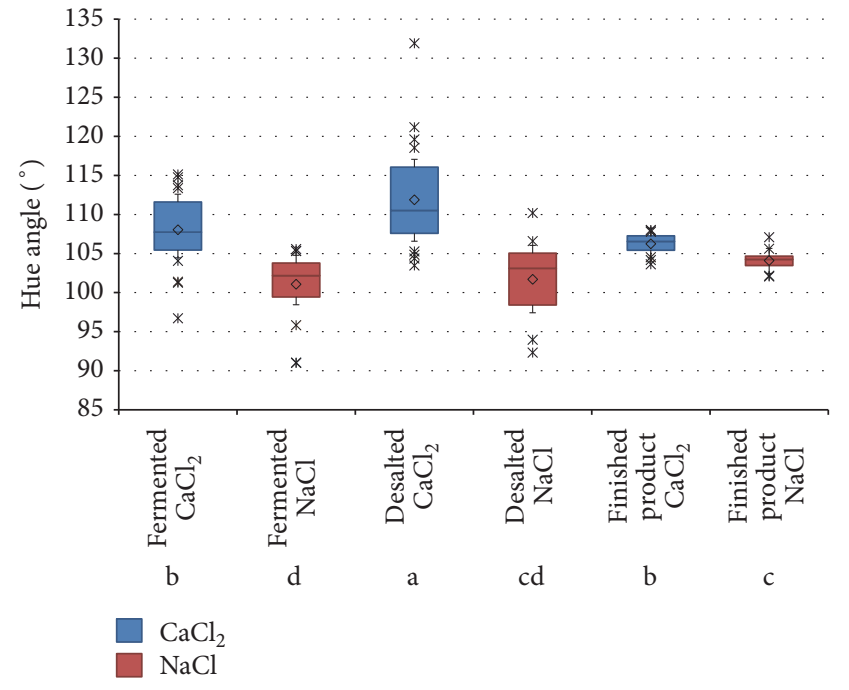

Figure 6: Mesocarp hue for cucumbers brined in $\mathrm{CaCl}_{2}$ and cucumbers brined in $\mathrm{NaCl}$ at the various stages in processing. Hue is measured as the degrees from red on a polar coordinate system with $90^{\circ}$ being in the yellow direction and $180^{\circ}$ being in the green direction. Hue values were significantly different at $P<0.05$ for treatments as signified by different lowercase letters below the treatment labels on the $x$-axis.

(UV) light from the sun would penetrate the surface of the brine. Eisenstat and Fabian [43,44] used salt stock of $16 \%$ and desalted stock of $3.8 \%$ salt to show that direct sunlight caused severe bleaching (loss of characteristic color) in a matter of hours unless the cucumber pickles were completely submerged in the $16 \%$ salt stock brine. The process of filling a fermentation tank with cucumbers would result in a short period of sun exposure time, and it may be enough to initiate photooxidation. Eisenstat and Fabian [44] also found that exposure to $\mathrm{CaCl}_{2}$ could cause slight bleaching of cucumbers in jars exposed to diffused light which is consistent with the

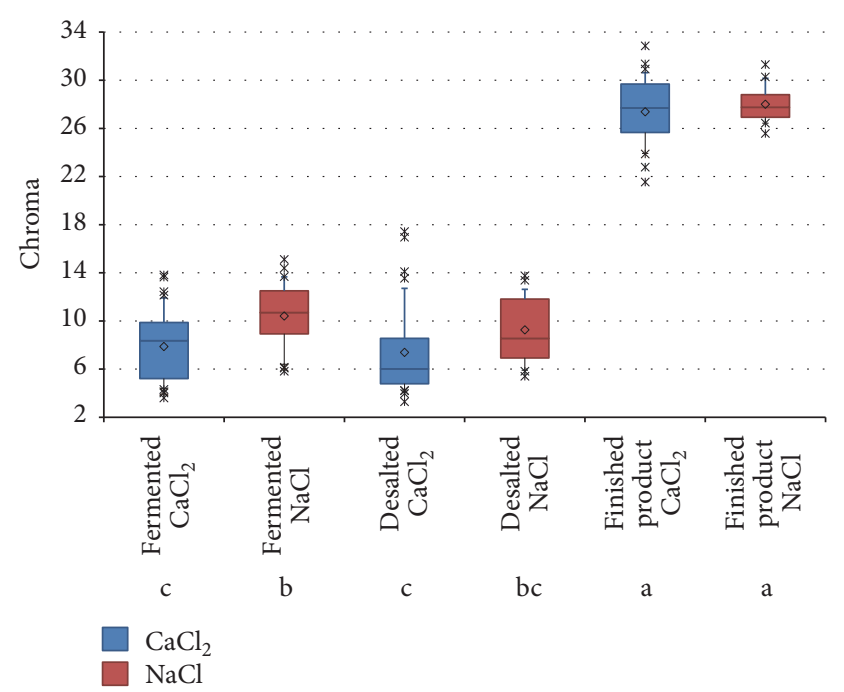

Figure 7: Mesocarp chroma for cucumbers brined in $\mathrm{CaCl}_{2}$ and cucumbers brined in $\mathrm{NaCl}$ at the various stages in processing. Chroma is measured radially from the pole and indicates the intensity of the color. Chroma values were significantly different at $P<$ 0.05 for treatments signified by different lowercase letters below the $x$-axis.

overall lower chroma value of the cucumbers fermented in $\mathrm{CaCl}_{2}$ brines (Figure 8). They also found that lightening of cucumber color increased from 1 to 6 weeks in the $3.8 \%$ salt desalted cucumbers. More recently, Buescher and Hamilton [45] found an increase in $L^{*}$ value by 10 and a $5^{\circ}\left(100\right.$ to $\left.95^{\circ}\right)$ change toward yellow in hue value for cucumbers fermented under incandescent lights compared to those fermented in the dark in brines composed of $5 \% \mathrm{NaCl}, 0.35 \% \mathrm{CaCl}_{2}$, $0.1 \%$ acetic acid, and $0.05 \%$ potassium sorbate. Additionally, Guillou et al. [46] found the hue of cucumbers fermented in $5 \% \mathrm{NaCl}, 0.2 \% \mathrm{CaCl}_{2}$, and $0.2 \%$ potassium sorbate to be between $105^{\circ}$ and $125^{\circ}$ during 18 weeks (126 days) of storage 


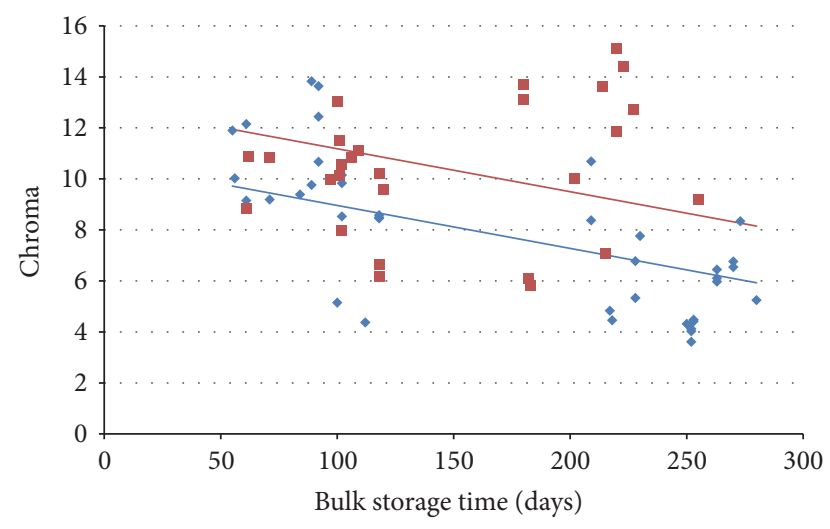

- $\mathrm{CaCl}_{2}$ fermentation

- $\mathrm{NaCl}$ fermentation

FIGURE 8: Differences in mesocarp chroma associated with greater length of time spent in bulk storage for fermented cucumbers brined in $\mathrm{CaCl}_{2}$ or $\mathrm{NaCl}$.

under $254 \mathrm{~nm}$ UV lights, while chroma decreased from 20 to 7. This hue is greener than the hue of these commercially fermented cucumbers, but the decrease in chroma matches our observed values fairly well (Figure 8). Eisenstat and Fabian $[43,44]$ found differences in observed bleaching defects depending on the light source: direct sunlight, an IR lamp, or a $210-328.7 \mathrm{~nm}$ UV lamp. Therefore, it is possible that there are multiple mechanisms occurring that affect the color of fermented cucumber. Further research to identify the mechanisms of color changes during fermentation and other products of photooxidation reactions could lead to the possibility of manipulating chlorophyll degradations to enable reduction or elimination of yellow 5 in cucumber pickle products.

\section{Conclusions}

Commercialization of the $\mathrm{CaCl}_{2}$ fermentation process enables elimination of sodium and an $80 \%$ reduction of chlorides in wastewaters. This study found that the color and texture quality were compromised when this process was implemented in a typical commercial environment using open tanks and air-purging. The quality changes occurred during fermentation and bulk storage and remained evident in the desalted cucumbers and finished pickle products. It appears that no further degradation of quality takes place in the later processing steps with the possible exception of the effects of pasteurization on texture. Significant evidence of photooxidation was apparent in the $\mathrm{CaCl}_{2}$ brined, fermented cucumbers, and there was a reduction in texture quality that could not be explained by compositional variation. Bloater defects were related to the minimal air-purging routine with the $\mathrm{CaCl}_{2}$ process, but implementation of typical purging routines in $\mathrm{CaCl}_{2}$ brines resulted in reduced bloater defects, complete fermentation, and stable bulk storage, so the minimal purging routine may not be necessary for future use of this process. Additional research is warranted to understand the tissue softening observed in the $\mathrm{CaCl}_{2}$ brined cucumber fermentation and to identify process changes or controls that will improve the quality of cucumbers fermented and stored with reduced salt.

\section{Disclosure}

Mention of a trademark or proprietary product does not constitute a guarantee or warranty of the product by the U.S. Department of Agriculture or North Carolina Agricultural Research Service nor does it imply approval to the exclusion of other products that may be suitable. USDA is an equal opportunity provider and employer.

\section{Conflicts of Interest}

The authors declare no conflicts of interest.

\section{Acknowledgments}

This study was funded by Mount Olive Pickle Company (Mt. Olive, NC) and the USDA-ARS Food Science Research Unit (Raleigh, NC) with partial support from Pickle Packers International (Washington, DC). The authors gratefully acknowledge Bay View Foods (Pinconning, MI), Gedney Foods (Chaska, MN), Mount Olive Pickle Company (Mt. Olive, NC), Hartung Brothers (Imlay City, MI and Bowling Green, $\mathrm{OH}$ ), and Swanson Pickle Company (Ravenna, MI) for conducting commercial scale fermentation in $\mathrm{CaCl}_{2}$ brines and providing samples for quality evaluation. They also thank Mrs. Sandra Parker for excellent administrative assistance and editorial review of the manuscript. This manuscript is based on a portion of the master's thesis research conducted by Erin K. McMurtrie under the direction of Dr. Suzanne D. Johanningsmeier at North Carolina State University, Raleigh, NC [47].

\section{References}

[1] United States Environmental Protection Agency, "National primary drinking water regulations," EPA 816-F-09-004, 2009.

[2] R. F. McFeeters, W. Coon, M. P. Palnitkar, M. Velting, and N. Fehringer, "Reuse of fermentation brines in the cucumber pickling industry," Cincinnati, Ohio; Springfield, Va.: EPA-600/2-78207 Environmental Protection Agency, 1978.

[3] I. M. Pérez-Díaz, R. F. McFeeters, L. Moeller et al., "Commercial Scale Cucumber Fermentations Brined with Calcium Chloride Instead of Sodium Chloride," Journal of Food Science, vol. 80, no. 12, pp. M2827-M2836, 2015.

[4] R. F. McFeeters and I. Pérez-Díaz, "Fermentation of cucumbers brined with calcium chloride instead of sodium chloride," Journal of Food Science, vol. 75, no. 3, pp. C291-C296, 2010.

[5] H. P. Fleming, R. L. Thompson, J. L. Etchells, R. E. Kelling, and T. A. Bell, "Bloater formation in brined cucumbers fermented by lactobacillus plantarum," Journal of Food Science, vol. 38, no. 3, pp. 499-503, 1973.

[6] R. N. Costilow, C. L. Bedford, D. Mlngus, and D. Black, "Purging of natural salt-stock pickle fermentations to reduce bloater damage," Journal of Food Science, vol. 42, no. 1, pp. 234-240, 1977. 
[7] R. N. Costilow and M. Uebersax, "Effects of Various Treatments on the Quality of Salt-Stock Pickles from Commercial Fermentations Purged with Air," Journal of Food Science, vol. 47, no. 6, pp. 1866-1868, 1982.

[8] H. P. Fleming, R. L. Thompson, J. L. Etchells, R. E. Kelling, and T. A. Bell, "Carbon dioxide production in the fermentation of brined cucumbers," Journal of Food Science, vol. 38, no. 3, pp. 504-506, 1973.

[9] J. L. Etchells and T. A. Bell, "Classification of yeasts from the fermentation of commercially brined cucumbers," Farlowia, vol. 4, no. 1, pp. 87-112, 1950.

[10] J. L. Etchells, A. F. Borg, and T. A. Bell, "Bloater formation by gas-forming lactic acid bacteria in cucumber fermentations," Applied Microbiology, vol. 16, no. 7, pp. 1029-1035, 1968.

[11] R. F. Mcfeeters, H. P. Fleming, and M. A. Daeschel, "Malic Acid Degradation and Brined Cucumber Bloating," Journal of Food Science, vol. 49, no. 4, pp. 999-1002, 1984.

[12] R. N. Costilow, K. Gates, and M. L. Lacy, "Molds in brined cucumbers: cause of softening during air-purging of fermentations," Applied and Environmental Microbiology, vol. 40, no. 2, pp. 417-422, 1980.

[13] K. Gates and R. N. Costilow, "Factors Influencing Softening of Salt-Stock Pickles in Air-Purged Fermentations," Journal of Food Science, vol. 46, no. 1, pp. 274-282, 1981.

[14] W. Franco and I. M. Pérez-Díaz, "Role of selected oxidative yeasts and bacteria in cucumber secondary fermentation associated with spoilage of the fermented fruit," Food Microbiology, vol. 32, no. 2, pp. 338-344, 2012.

[15] E. M. Wilson, S. D. Johanningsmeier, and J. A. Osborne, "Consumer Acceptability of Cucumber Pickles Produced by Fermentation in Calcium Chloride Brine for Reduced Environmental Impact," Journal of Food Science, vol. 80, no. 6, pp. S1360-S1367, 2015.

[16] I. M. Pérez-Díaz and R. F. McFeeters, "Preparation of a Lactobacillus Plantarum Starter Culture for Cucumber Fermentations That Can Meet Kosher Guidelines," Journal of Food Science, vol. 76, no. 2, pp. M120-M123, 2011.

[17] J. L. Etchells, T. A. Bell, H. P. Fleming, R. E. Kelling, and R. L. Thompson, Q-BAT instruction sheet with bloater chart, Advisory statement published and distributed by Pickle Packers International, Inc. St. Charles, IL, 1974.

[18] H. P. Fleming, R. L. Thompson, T. A. Bell, and R. J. Monroe, "Effect of brine depth on physical properties of brine-stock cucumbers," Journal of Food Science, vol. 42, no. 6, pp. 1464-1470, 1977.

[19] R. L. Thompson, H. P. Fleming, D. D. Hamann, and R. J. Monroe, "Method for determination of firmness in cucumber slices," Journal of Texture Studies, vol. 13, no. 3, pp. 311-324, 1982.

[20] Y. Yoshioka, H. Horie, M. Sugiyama, and Y. Sakata, "Quantifying cucumber fruit crispness by mechanical measurement," Breeding Science, vol. 59, no. 2, pp. 139-147, 2009.

[21] Official Methods of Analysis of AOAC Intl. Method 968.31, AOAC Intl., Gaithersburg, Md., USA, 17 edition, 2000.

[22] H. P. Fleming, R. F. McFeeters, and F. Breidt, "Fermented and acidified vegetables," in Compendium of Methods for the Microbiological Examination of Foods, pp. 521-532, American Public Health Association, 4th edition, 2001.

[23] R. W. Buescher and C. Burgin, "Diffusion plate assay for measurement of polygalacturonase activities in pickle brines," Journal of Food Biochemistry, vol. 16, no. 1, pp. 59-68, 1992.
[24] "Code of Federal Regulations, Title 21, Food and drugs (21CFR184.1193), Calcium chloride, Office of the Federal Register, National Archives and Records Service, General Services Administration," Tech. Rep., 2011.

[25] W. A. Sistrunk and J. Kozup, "Influence of Processing Methodology on Quality of Cucumber Pickles," Journal of Food Science, vol. 47, no. 3, pp. 949-953, 1982.

[26] L. B. Rosenberg, Texture of pickles produced from commercial scale cucumber fermentation using calcium chloride instead of sodium chloride, NCSU ETD. Student thesis, 2013.

[27] M. J. Cho and R. W. Buescher, "Potential Role of Native Pickling Cucumber Polygalacturonase in Softening of Fresh Pack Pickles," Journal of Food Science, vol. 77, no. 4, pp. C443-C447, 2012.

[28] T. A. Bell, J. L. Etchells, and J. D Jones, "Softening of commercial cucumber salt-stock in relation to polygalacturonase activity," Food Technology, vol. 4, no. 4, pp. 157-163, 1950.

[29] R. W. Buescher, J. M. Hudson, and J. R. Adams, "Utilization of calcium to reduce pectinolytic softening of cucumber pickles in low salt conditions," Lebensmittel-Wissenschaft \& Technologie, vol. 14, no. 2, pp. 65-69, 1981.

[30] R. W. Buescher, J. M. Hudson, and J. R. Adams, "Inhibition of polygalacturonase softening of cucumber pickles by calcium chloride," Journal of Food Science, vol. 44, no. 6, pp. 1786-1787, 1979.

[31] T. A. Bell, L. J. Turney, and J. L. Etchells, "Influence of different organic acids on the firmness of fresh-pack pickles," Journal of Food Science, vol. 37, no. 3, pp. 446-449, 1972.

[32] L. R. Howard, P. Burma, and A. B. Wagner, "Firmness and Cell Wall Characteristics of Pasteurized Jalapeño Pepper Rings Affected by Calcium Chloride and Acetic Acid," Journal of Food Science, vol. 59, no. 6, pp. 1184-1186, 1994.

[33] R. F. McFeeters, M. B. Balbuena, and H. P. Fleming, "Softening Rates of Fermented Cucumber Tissue: Effects of $\mathrm{pH}$, Calcium, and Temperature," Journal of Food Science, vol. 60, no. 4, pp. 786-788, 1995.

[34] R. Hutcheson, M. D. Engelmann, and I. F. Cheng, "A hypothesis for the basis of the pro-oxidant nature of calcium ions," BioMetals, vol. 17, no. 6, pp. 605-613, 2004.

[35] R. W. Buescher and C. Burgin, "Effect of Calcium Chloride and Alum on Fermentation, Desalting, and Firmness Retention of Cucumber Pickles," Journal of Food Science, vol. 53, no. 1, pp. 296-297, 1988.

[36] M. Rodrigo and A. Alvarruiz, "The influence of fermentation and pasteurization on the texture of cucumber pickles," Journal of Food Engineering, vol. 7, no. 2, pp. 113-125, 1988.

[37] I. J. Jeon, W. M. Breene, and S. T. Munson, "Texture of cucumbers: correlation of instrumental and sensory measurements," Journal of Food Science, vol. 38, no. 2, pp. 334-337, 1973.

[38] R. W. Buescher, C. Hamilton, J. Thorne, and M. J. Cho, "Elevated calcium chloride in cucumber fermentation brine prolongs pickle product crispness," Journal of Food Quality, vol. 34, no. 2, pp. 93-99, 2011.

[39] J. W. Heaton, R. W. Lencki, and A. G. Marangoni, "Kinetic model for chlorophyll degradation in green tissue," Journal of Agricultural and Food Chemistry, vol. 44, no. 2, pp. 399-402, 1996.

[40] I. D. Jones, R. C. White, and E. Gibbs, "Some pigment changes in cucumbers during brining and storage," Food Technology, vol. 16, no. 3, pp. 96-102, 1962. 
[41] S. M. Gupte, H. M. El-Bisi, and F. J. Francis, "Kinetics of Thermal Degradation of Chlorophyll in Spinach Puree," Journal of Food Science, vol. 29, no. 4, pp. 379-382, 1964.

[42] R. C. White, I. D. Jones, and E. Gibbs, "Determination of Chlorophylls, Chlorophyllides, Pheophytins, and Pheophorbides in Plant Material," Journal of Food Science, vol. 28, no. 4, pp. 431436, 1963.

[43] L. Eisenstat and F. W. Fabian, "Factors which produce bleaching of pickles-I," The Glass Packer, 50-51, 78, 1953.

[44] L. Eisenstat and F. W. Fabian, "Factors which produce bleaching of pickles-II," The Glass Packer, vol. 70, 72, 1953.

[45] R. Buescher and C. Hamilton, "Protection of cucumber pickle quality by CaNa2EDTA," Journal of Food Quality, vol. 23, no. 4, pp. 429-441, 2000.

[46] A. A. Guillou, J. D. Floros, and M. A. Cousin, "Calcium Chloride and Potassium Sorbate Reduce Sodium Chloride used during Natural Cucumber Fermentation and Storage," Journal of Food Science, vol. 57, no. 6, pp. 1364-1368, 1992.

[47] E. K. McMurtrie, Quality of cucumbers fermented in acidified and non-acidified calcium chloride brines for Reduced Environmental Impact of Brining Operations [M.S. Thesis], North Carolina State University, Raleigh, NC, 2016. 


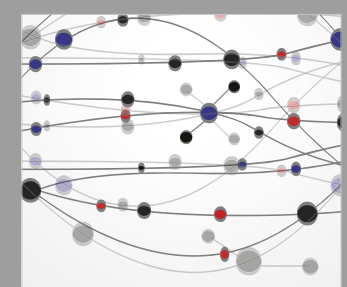

The Scientific World Journal
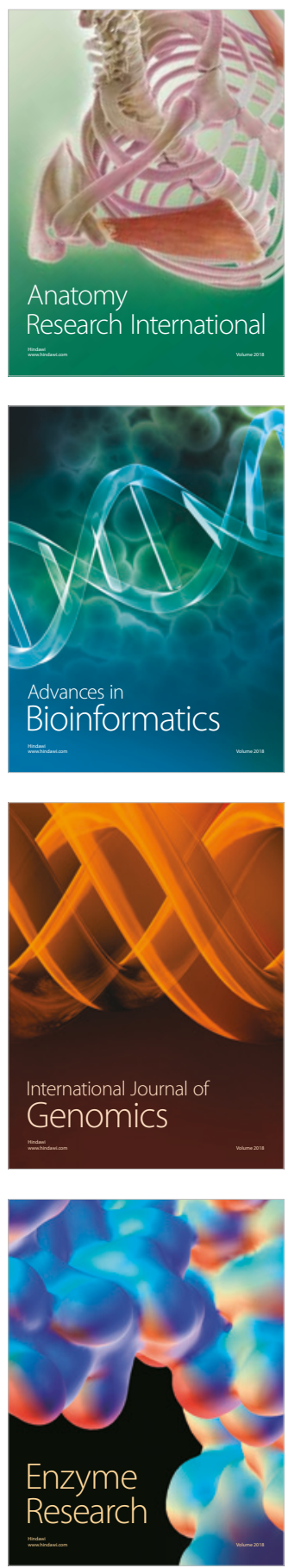
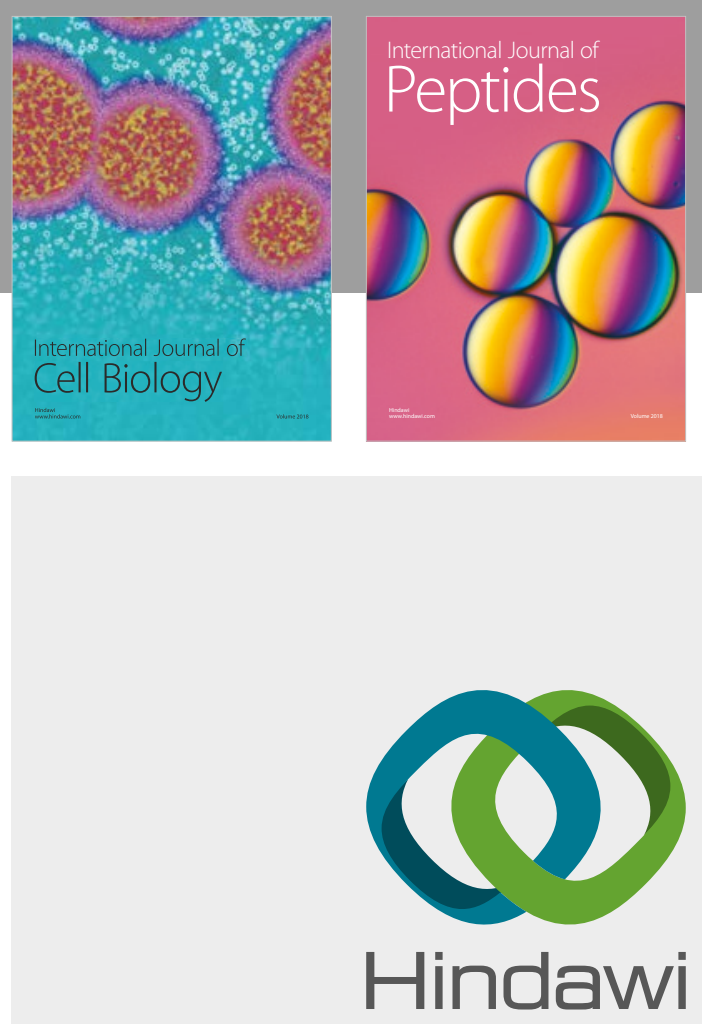

Submit your manuscripts at

www.hindawi.com
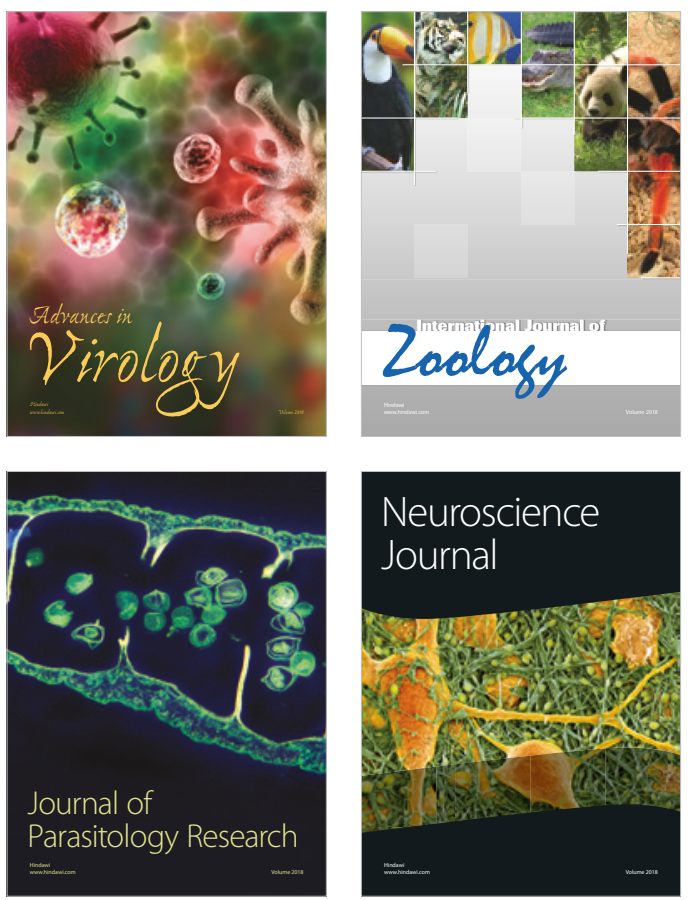
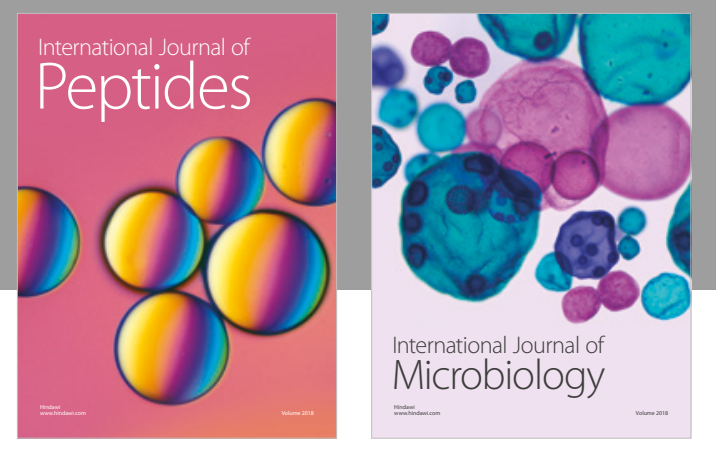

nternational Journal of Microbiology
Journal of
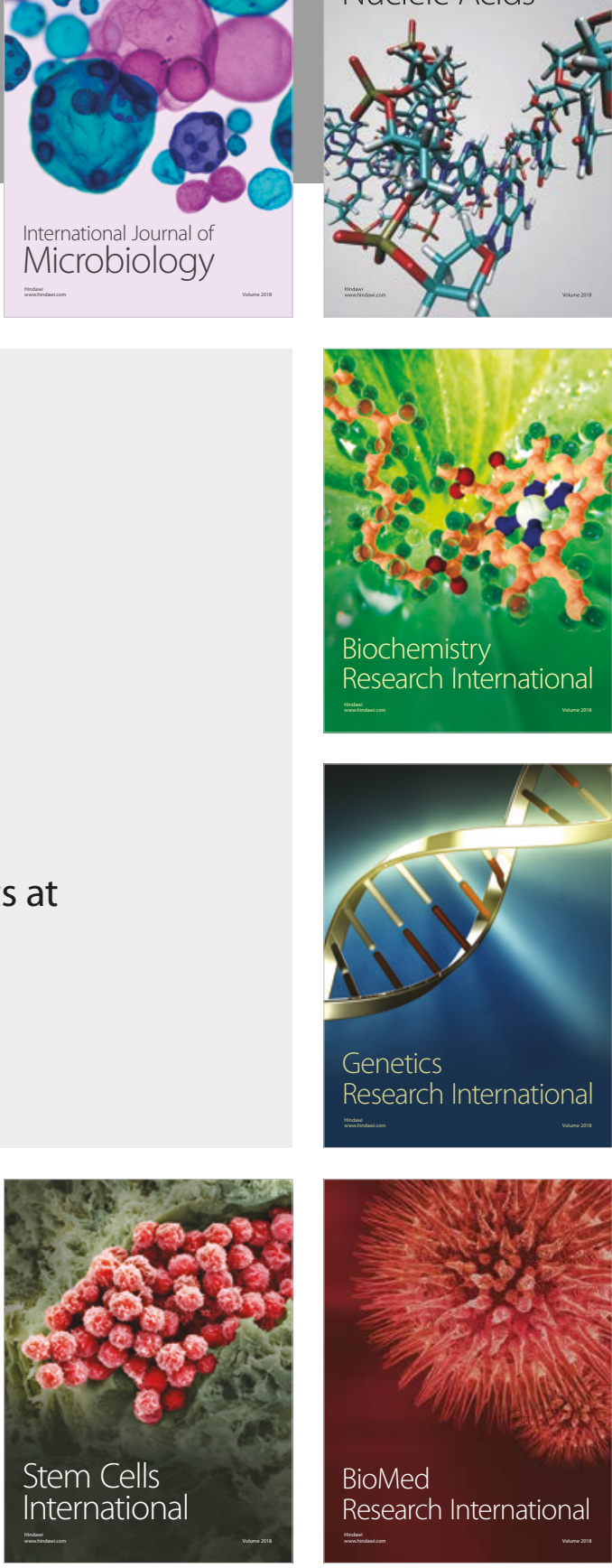
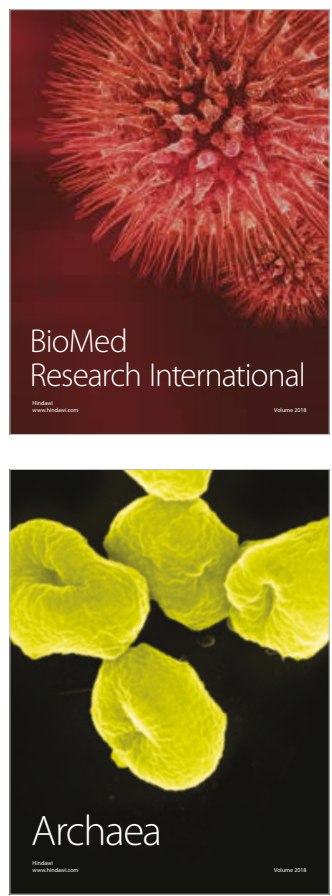